\title{
Frontières
}

\section{Espaces émergents}

\section{Henri Barras}

Volume 14, numéro 1, automne 2001

Où est la marge?

URI : https://id.erudit.org/iderudit/1074161ar

DOI : https://doi.org/10.7202/1074161ar

Aller au sommaire du numéro

Éditeur(s)

Université du Québec à Montréal

ISSN

1180-3479 (imprimé)

1916-0976 (numérique)

Découvrir la revue

Citer cet article

Barras, H. (2001). Espaces émergents. Frontières, 14(1), 56-57.

https://doi.org/10.7202/1074161ar

Ce document est protégé par la loi sur le droit d'auteur. L'utilisation des services d'Érudit (y compris la reproduction) est assujettie à sa politique d'utilisation que vous pouvez consulter en ligne.

https://apropos.erudit.org/fr/usagers/politique-dutilisation/
Cet article est diffusé et préservé par Érudit.

Érudit est un consortium interuniversitaire sans but lucratif composé de l’Université de Montréal, l'Université Laval et l'Université du Québec à Montréal. Il a pour mission la promotion et la valorisation de la recherche. https://www.erudit.org/fr/ 


\section{ESPACES ÉMERGENTS}

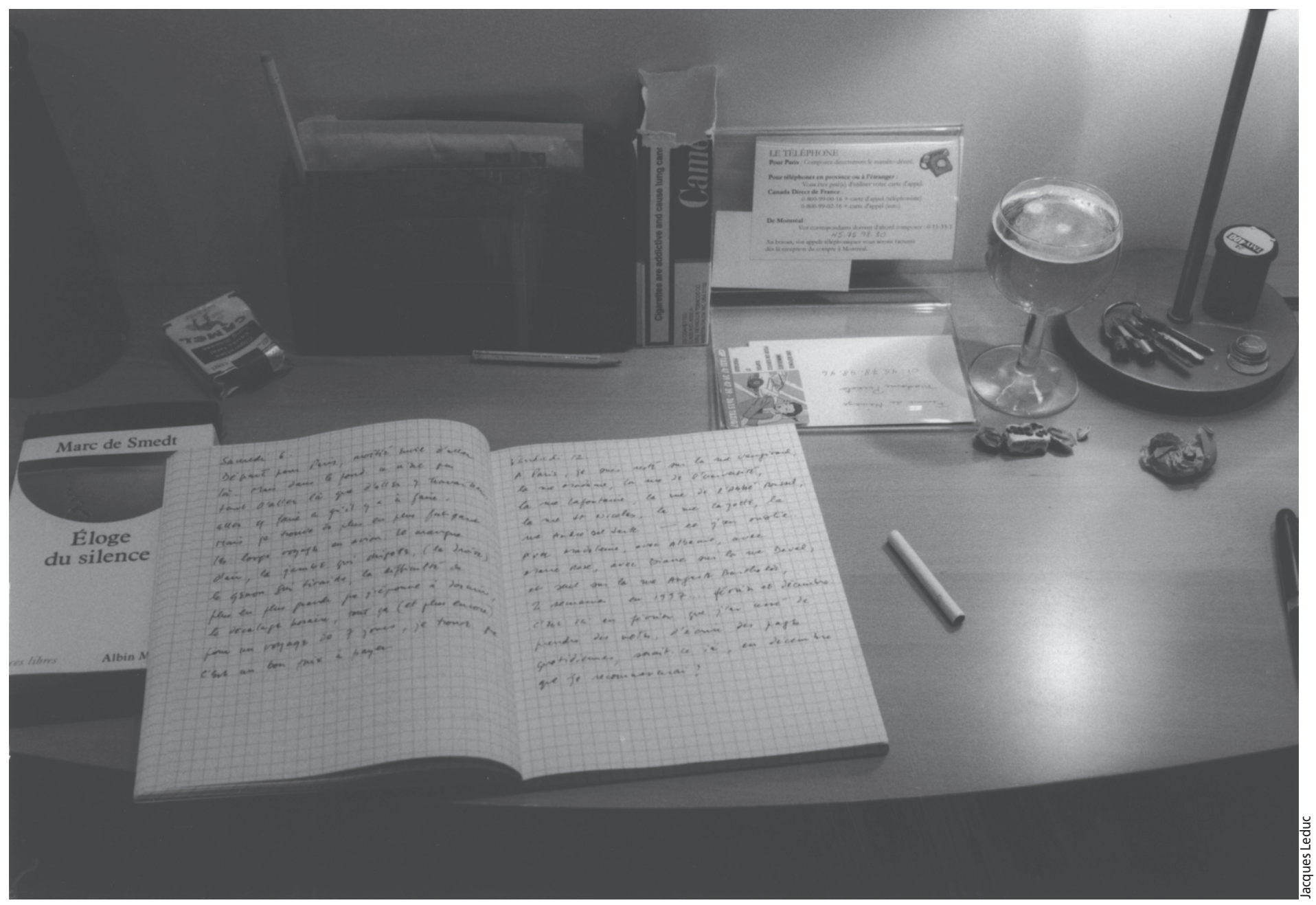

Henri Barras, producteur délégué et concepteur du projet Espaces émergents.

Faites de la musique, organisme de démocratisation de la culture installé dans le quartier Hochelaga-Maisonneuve depuis 1993 est porteur d'un projet issu du Sommet du Québec de la jeunesse ayant pour titre Espaces émergents. Il s'est donné pour objectifs de mettre en réseau les créateurs émergents, de soutenir la production et la diffusion de leurs œuvres et de dresser annuellement une vitrine de ces nouvelles formes d'art et des nouvelles manières de faire l'art. Une première activité s'est déroulée à Montréal, lors du long week-end de l'Action de grâces. Elle affichait un slogan qui illustrait bien les diverses propositions artistiques venues de l'ensemble des régions du Québec: Lorsque la marge nourrit la norme et la transforme.
Ceux qui œuvrent dans le domaine de la culture au Québec savent ce que la marge signifie. Savent en tout cas que son espace est bien plus vaste que celui dévolu à la norme soutenue pourtant à grands renforts de dollars et de propagande étouffant, de fait, toute tentative de création pourtant nécessaire à l'équilibre des sociétés soucieuses de se développer.

Ainsi la marge est devenue un vaste désert pour les créateurs refusant de jouer 


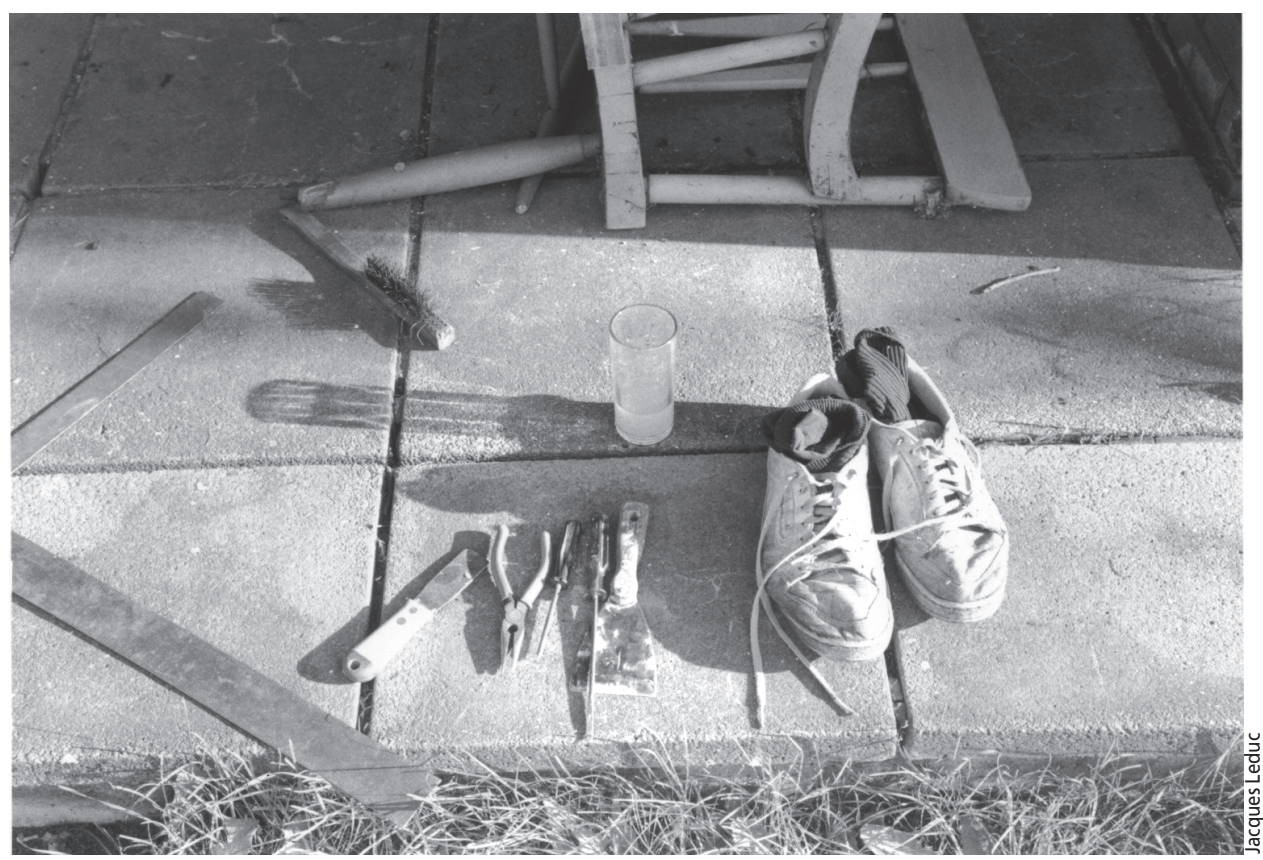

le jeu de la relève soutenu par l'industrie; s'objectant à suivre le chemin de l'histoire tracé d'avance par les intellectuels fonctionnarisés ; niant aux convenances le privilège d'entraver la liberté de créer. Lorsque l'on constate de surcroît que tout ce qui est en dehors des limites des grands centres Montréal et éventuellement Québec - se trouve d'office placé dans la marge par les paliers de gouvernements, les institutions et les médias, leurs porte-parole, on est en droit de se poser des questions non pas sur ce qui se trouve marginalisé mais bien sur l'espace ratatiné dévolu à la culture. La culture officielle s'entend.

La conférence de presse pour dévoiler la programmation de ces Espaces émergents avait été convoquée pour le 11 septembre à 11 heures. Les télévisions refusèrent l'invitation dès lors qu'aucune tête d'affiche n'était à disposition de leurs caméras. Aucun journaliste par ailleurs ne se présenta, tous étant sur le fil de presse ou devant leurs écrans, à l'affût de nouvelles sur les événements s'étant déroulés une heure plus tôt à New York. Seul le chroniqueur d'un journal que certains comparent à un bulletin paroissial s'est trouvé, paumé, au milieu d'artistes éberlués au cœur d'une usine requinquée pour l'occasion. Si le scribouillard considéra que le slogan de la manifestation était éculé, les artistes, eux, se sentirent concernés par les événements et en terrain connu, même s'il était, pourtant, soudainement devenu plus désertique encore. L'un d'eux brisa l'état d'hébétude dans lequel l'assistance allait plonger et donna le ton à cette réunion devenue insolite devant les enjeux nouveaux du monde occidental. Il déclara que rien ne changerait pour les créateurs coutumiers des états
Pour se mettre au goût du jour et endosser la doctrine du « tout culturel » qui donne le change à cette promesse d'une société des loisirs jamais pourtant avenue, le ministère de la Culture d'aujourd'hui, même en changeant de titre, n'en est pas moins celui qui gère au nom du gouvernement les Affaires culturelles d'hier. Et les artistes reconnus et bien évidemment convenus, de suivre le mode d'emploi habituel. Le fric est offert aux producteurs d'objets l'art est tout ce qui est inutile - à ces artistes patentés qui doivent faire preuve d'une promesse d'exposition dans une galerie reconnue et forcément subventionnée. De la Culture ou des Affaires culturelles ? Peuton par ailleurs fermer les yeux sur un système d'éducation qui néglige l'apprentissage des arts sous prétexte que l'école doit permettre aux futurs adultes d'être au nombre de la relève dont le monde a besoin pour se perpétuer? Identique ? En se répétant? Passons sur les irresponsabilités des ministères et des institutions. Doit-on esquiver celles des divers organismes de presse qui n'entretiennent le «peuple» que de ce qui leur rapporte?

Combien de millions de Québécois, dès lors, se comptent dans les marges? Il est terrifiant qu'à l'aube du XXI siècle on en soit encore, en termes de culture, aux temps de la barbarie. Qu'on insupporte encore ceux dont la différence est une nécessité vitale et dont notre survie dépend, de leur existence et de leur dissidence.

Or, partout où le terme culture est devenu synonyme de loisir; partout où celui d'élitiste est insulte aux lèvres des parvenus, les tenants de la marge doivent être soutenus. Si ce n'était que pour éprouver le sens véritable du mot liberté qui ne peut s'épanouir encore pleinement que dans le domaine de la création.

Du renouvellement! C'est du moins ce que nous pensons de la marge - territoire fécond des cultures émergentes.

Où la création? En marge! Et la marge nourrit la norme et la transforme. 